\begin{tabular}{c} 
The Open Conference Proceedings \\
Jourtham open \\
CrossMark \\
Content list available at: www.benthamopen.com/TOPROCJ/ \\
DOI: $10.2174 / 2210289201607020055$ \\
\hline
\end{tabular}

\title{
Chlorophyll Fluorescence and Colorimetric Analysis for Monitoring the Algal Development on Biocide-Treated Stone
}

\author{
Stéphanie Eyssautier-Chuine ${ }^{\mathrm{a}, *}$, Nathalie Vaillant-Gaveau ${ }^{\mathrm{b}}$, Maxime Gommeaux ${ }^{\mathrm{a}}$, Céline \\ Thomachot-Schneider ${ }^{\mathrm{a}}$, Jessica Pleck ${ }^{\mathrm{c}}$ and Gilles Fronteau ${ }^{\mathrm{a}}$ \\ ${ }^{a}$ Groupe d'Étude sur les Géomatériaux et les Environnements naturels, Anthropiques et Archéologiques EA 3795 (GE- \\ GENAA) Université de Reims Champagne-Ardenne, Reims, France; \\ ${ }^{b}$ Unité de Recherche Vignes et Vins de Champagne URVVC EA 4707. Laboratoire de Stress, Défense et Reproduction \\ des Plantes Université de Reims Champagne-Ardenne, Reims, France \\ ${ }^{c}$ Centre de Ressources Technologiques en Chimie (CERTECH), Seneffe, Belgique
}

\begin{abstract}
The present study used two non destructive technics, chlorophyll fluorescence and colorimetry to assess the Chlorella vulgaris growth on stone surface treated by experimental treatments for preventing biofouling. A protocol for laboratory tests was set up, consisting of inoculating treated slabs stone with a suspension of an algae culture (Chlorella vulgaris), that is a well known monument colonizing organism. The biofouling test was carried out under fluorescent lights for four weeks at room temperature which was $20^{\circ} \mathrm{C}$ and monitored by chlorophyll a fluorescence and colorimetry analysis. These techniques are rapid, non-invasive, and reliable.

Treatments were introduced by mixing a tetraethoxysilane base with different ingredients: chitosan and/or silver nitrate for biocide effect and/or hydrophobic silica for water repellency.

Results revealed four different patterns of algal development. The stones treated with the product containing chitosan and silver nitrate did not show any difference in their fluorescence signal as compared with the untreated stones (control). The stones treated with the product containing only silver nitrate showed biocide effect two weeks after the start of the experiment. The product containing silver nitrate, chitosan and hydrophobic silica at low concentrations completely inhibited algal development in the long term, the similar product with the same compounds at a higher concentration only delayed algal development by 1-2 weeks.

This suggests that low concentrations of the products have a synergistic effect, that is lost if they occur in excess. In the present study, chlorophyll a fluorescence proved to be a valuable tool in detecting damage in the photosynthetic system of organisms and as a useful complement to other conventional measurements such as colorimetry.
\end{abstract}

Keywords: Algae, biocide, chlorophyll a fluorescence, color, limestone.

\section{INTRODUCTION}

Natural stone has been used throughout history for its strength and resistance over time. Nevertheless, many building stones and sculptures are subjected to weathering effects such as biodegradation. Biological activity of microorganisms such as bacteria, cyanobacteria, fungi and lichen contributes to foul the stones. The impact on cultural heritage monuments is not only unsightly with the heterogeneous changes of color but is also highly damaging to the structure of the stone and can lead to irreversible damage if the crust is detached [1]. Microorganisms influence the deterioration of stone by releasing organic acids that cause corrosive effect on the substrate [2, 4]. Moreover they secrete extracellular polymeric substances (EPS) which reduce desiccation and provide a reservoir of nutrients [3,5].

\footnotetext{
* Address correspondence to this author at the Groupe d'Étude sur les Géomatériaux et les Environnements naturels Anthropiques et Archéologiques EA 3795 (GEGENAA) Université de Reims Champagne-Ardenne, Reims, France; Tel: +33 326773 636; Fax: +33 326 773 694; Email: stephanie.eyssautier@univ-reims.fr
} 
Such biodegradation results from the bioreceptivity of the materials [6] including many intrinsic stone characteristics such as petrophysical properties, mineralogical nature, surface roughness [7] and the environmental and climatic conditions [8,9]. Biodeterioration and its impact on Cultural Heritage have been widely studied [1, 4, 10] and many techniques are used to quantify its development and its removal by biocide treatments [11 - 14].

This study aimed at assessing the effects of four biocide treatments with two non destructive techniques: the monitoring of color changes in the stone surface is widely applied in studies of stone monuments to measure the spread of microorganisms [15 - 17]; chlorophyll $a$ fluorescence is used to measure the photosynthetic activity of phototrophic organisms [18]. The latter method is commonly used by plant physiologists. In recent years, chlorophyll $a$ fluorescence analysis has been applied in the conservation of stone monuments to study the development of microorganisms on stone and their ability to resist environmental stress [14]. The fluorescence arising from chlorophyll is almost exclusively associated with photosystem II, which is sensitive to a wide range of environmental variations. Chlorophyll $a$ fluorescence provides considerable information about the effects of plant stresses [19]. Biocides are used to induce stress on microorganisms by inhibiting the photosynthetic process [14]. Treatments tested in this study were developed to prevent biological development in building stones. They were made by sol-gel process with tetraethoxysilane (TEOS) as a base associated with three active components: silver nitrate, chitosan and hydrophobic silica.

Table 1. Physical properties of the Dom stone.

\begin{tabular}{|l|c|}
\hline Water porosity P $(\%)$ & $30 \pm 2.7$ \\
\hline Capillary absorption & $146 \pm 51$ \\
$\cdot$ Weight increase per surface unit $\mathrm{C} 1\left(\mathrm{~g} / \mathrm{m}^{2} / \mathrm{s}^{1 / 2}\right)$ & $26.8 \pm 6$ \\
\hline Wet fringe migration $\mathrm{C}^{2}\left(\mathrm{~m} / \mathrm{s}^{1 / 2}\right)$ & $8.6 .10^{-12}$ \\
\hline Diffusivity coefficient $($ at $33 \% \mathrm{HR}) \delta(\mathrm{kg} / \mathrm{m}$. s.Pa) & \\
\hline
\end{tabular}

Table 2. Products composition. The concentration $(\mathrm{g} / \mathrm{L})$ of the components increases according to the number of sign $(+)$ and goes to the lowest concentration with $(+)$ to the highest concentration with $(+++)$.

\begin{tabular}{|c|c|c|c|c|}
\hline \multicolumn{5}{|c|}{ Products composition } \\
\hline Name & TEOS & AgNO $_{3}$ & Chitosan & Hydro. Silica \\
\hline P1 & ++ & ++ & + & ++ \\
\hline P2 & ++ & + & + & + \\
\hline P3 & ++ & + & + & \\
\hline
\end{tabular}

The properties of these components are well known: silver like various metals is a classic biocide for bacteria and plants [20]; chitosan is a relatively new biodegradable component used for its antibacterial [21, 22] and algaecide properties [23]; hydrophobic silica is used in many fields such as the glass industry for its super hydrophobic behavior [24], which provides self cleaning and anti biofouling properties. Here we attempted to combine TEOS with one, two and all of the components in different concentrations to reach optimal biocide effectiveness and to identify the mechanism in the photosynthetic process.

\section{MATERIALS AND METHODOLOGY}

\subsection{Building Stone}

The stone selected was the Dom stone (Bajocian, $180 \mathrm{My}$ ) widely used in buildings and monuments in the northern part of France and the southern part of Belgium. It is a limestone with a characteristic russet color due to its high iron content $(0.5 \%)$. The Dom stone is a bioclastic limestone [25]; the microfacies is composed of calcitic debris $(50 \%)$ : numerous echinoderm ossicles $(25 \%)$ in a syntaxical cement, shell fragments $(10 \%)$, micritic grains (10\%) and few quartz grains $(5 \%)$ scattered in the rock. The spar cementation is partial and remains of high intergranular macroporosity. In addition, the petrophysical properties of the stone (Table 1), measured thank to the European Committee for Standardization EN 1936 [26], EN 1925 [27], EN 15803 [28], showed a well connected high porosity that facilitates water vapor transfer into the stone. Thus, petrographical and petrophysical properties influence stone weathering and favor a significant bioreceptivity of the stone. Alterations observed in Dom stone are heterogeneous disintegration and desquamation with deeper eroded layers on the rock surface [9] and an important biocolonization. 
Moreover, the high capillary coefficients facilitate the application and the impregnation of the products on the stone.

\subsection{Products}

Four products were produced by sol-gel process at room temperature and were made with a TEOS base (tetraethoxysilane) at low concentration used as a precursor for the polymerization of products. TEOS is well known in stone conservation and is widely used for consolidants or water repellents. Here, TEOS was used at a low concentration, only as a precursor for the polymerization of the sol-gel.

The other components were chitosan, silver nitrate and hydrophobic silica. Chitosan was added for its bacteriostatic activity [22, 29] and was commercially acquired (from Sigma-Aldrich). It is a deacetylated derivative of chitin which is an important constituent of the cell walls of many fungi and crustaceans. Silver nitrate is a chemical component with antimicrobial properties and was commercially acquired (from Sigma-Aldrich). Water repellency was carried out by the hydrophobic silica or fumed silica. The latter consists of silica nanoparticles, originally hydrophilic, but chemically transformed to bind silane or siloxane functional groups for hydrophobic properties; it was commercially acquired (Aerosil $^{\circledR} \mathrm{R}$ from Evonik Industries AG).

The TEOS proportion remained constant and the other components varied according to their occurrence and their proportion (Table 2). P1 was composed of TEOS base, chitosan, silver nitrate and hydrophobic silica. The last two components were in higher proportion than in the other products. P2 included TEOS base, chitosan, silver nitrate and hydrophobic silica. P3 was made of TEOS base, chitosan and silver nitrate and P4 was composed of TEOS base and only silver nitrate.

Test weeks

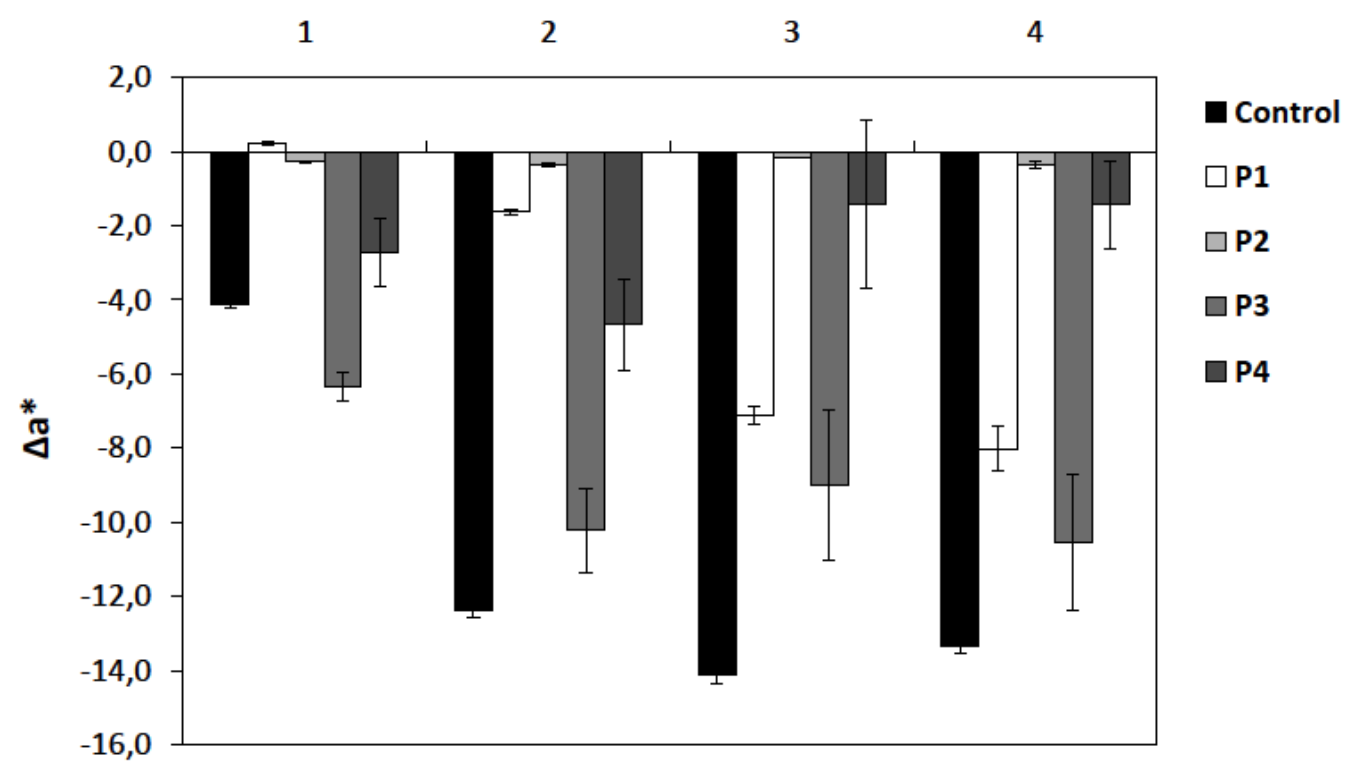

Fig. (1). $\Delta \mathrm{a}^{*}$ of control and of treated stones calculated from a ${ }^{*}$ before incubation and after 1, 2, 3 and 4 weeks of incubation. Values corresponding to the mean of $\Delta \mathrm{a}^{*}$ from the three slabs of each treatment.

\subsection{Experimental Procedure}

An accelerated biocolonization test on building stone was set up by inoculating stone slabs (dimension: $5 \times 5 \times 1 \mathrm{~cm}$ ) with a suspension of Chlorella vulgaris culture for 24 hours. Triplicate slabs were used for each treatment and for the control. Chlorella vulgaris var. Viridis (Chodat) was purchased from the Culture Collection of Algae and Protozoa (Dunstaffnage Marine Laboratory, Scotland; strain reference CCAP 211/12). Algae were first grown in a liquid culture medium composed of demineralized water with BG11- (a medium from Sigma-Aldrich. concentrated 50 times). It was diluted to get a similar algal concentration for every test, as measured by the chlorophyll $a$ absorbance control at 665 $\mathrm{nm}$ and $653 \mathrm{~nm}$ using spectrophotometry. Stone slabs were placed in Plexiglass cups. The cups were filled to the top with algal suspension, $5 \mathrm{~mm}$ above the stone surface. Gravitational settling of the algae was carried out by letting the slabs stand for 24 hours to obtain a homogeneous seeding. Then, the broth was removed and demineralized water was 
added up to $0.5 \mathrm{~cm}$ from the bottom of each sample. Water was added regularly over the entire incubation period to ensure that the stones were continually kept wet by means of capillary absorption. The biofouling test was carried out using fluorescent lights (Sylvania Gro-Lux) for four weeks at room temperature $\left(20^{\circ} \mathrm{C}\right)$.

\subsection{Method of Analysis of Biofouling}

\subsubsection{Colorimetry}

The visual algae development of stone was measured by colorimetry using a Chroma Meter CR-400 by KonicaMinolta with a light projection tube CR-A33c of $11 \mathrm{~mm}$ diameter (corresponding to the measurement zone). Calibrations were carried out with a white ceramic plate CR-A43. Values are given in the CIELAB system [30]. These parameters determine the color location in the color space: $\mathrm{L}^{*}$ indicates lightness $(0=$ absolute black, $100=$ absolute white); $a^{*}$ and $b^{*}$ are the chromaticity coordinates. $a^{*}$ is the position between green $\left(a^{*}<0\right)$ and red $/$ magenta $\left(a^{*}>0\right)$; $b^{*}$ is the position between blue $\left(b^{*}<0\right)$ and yellow $\left(b^{*}>0\right)$. Nine measurements were performed on the whole slabs' surface.

The global color variation $\left(\Delta \mathrm{E}^{*}{ }_{\mathrm{ab}}\right)$ was calculated from the three color parameters with the formula:

$\Delta \mathrm{E}^{*}{ }_{\mathrm{ab}}=\sqrt{\Delta \mathrm{L}^{* 2}+\Delta \mathrm{a}^{* 2}+\Delta \mathrm{b}^{* 2}}$. The $\Delta \mathrm{L}^{*}, \Delta \mathrm{a}^{*}$ and $\Delta \mathrm{b}^{*}$ were the differences between measurements before and after treatment. Nine measurements were done on every stone slab. $\Delta \mathrm{E}^{*}{ }_{\mathrm{ab}}$ and $\Delta \mathrm{a}^{*}$ were the average calculated from the triplicates.

$\Delta \mathrm{E}^{*}{ }_{\mathrm{ab}}$ was used to measure the color change induced by treatment and $\Delta \mathrm{a}^{*}$ was used as an indicator of greening during the incubation test. It was calculated from the measurements after 24 hours of inoculation and every week throughout the one-month incubation.

\subsubsection{Chlorophyll a Fluorescence}

The chlorophyll $a$ fluorescence (ChlaF) of algae was quantified directly in the stone slabs with an IMAGING-PAM Chlorophyll Fluorometer (Walz, Effeltrich, Germany). The measuring system applies an array of blue light emitting diodes (LEDs) (peak wavelength, $470 \mathrm{~nm}$ ) as saturating light pulses. The frequency of the pulses was adjusted to $10 \mathrm{~Hz}$. Measurements were carried out at a distance of $5 \mathrm{~cm}$ between the camera and the slab's given $25 \times 34 \mathrm{~mm}$ surface area. The image captured by the charge-coupled device (CCD) camera had a $640 \times 480$ pixel size.

\begin{tabular}{|c|c|c|c|c|c|c|c|c|c|c|}
\hline \multirow{2}{*}{ Time } & \multicolumn{2}{|c|}{ Control } & \multicolumn{2}{|c|}{ P1 treatment } & \multicolumn{2}{|c|}{ P2 treatment } & \multicolumn{2}{|c|}{ P3 treatment } & \multicolumn{2}{|c|}{ P4 treatment } \\
\hline & $\mathrm{Fv} / \mathrm{Fm}$ & $\mathrm{Fm}$ & $\mathrm{Fv} / \mathrm{Fm}$ & $\mathrm{Fm}$ & $\mathrm{Fv} / \mathrm{Fm}$ & $\mathrm{Fm}$ & $\mathrm{Fv} / \mathrm{Fm}$ & $\mathrm{Fm}$ & $\mathrm{Fv} / \mathrm{Fm}$ & $\mathrm{Fm}$ \\
\hline 1 week & & & & & & & & & & \\
\hline 2 weeks & & & & & & & & & & \\
\hline 3 weeks & & & & & & & & & & \\
\hline 4 weeks & & & & & & & & & & \\
\hline
\end{tabular}

Fig. (2). Fluorescence imaging of the dynamic evolution of Chlorella vulgaris inoculated on control (untreated stones) and treated stones. Samples were 30 min dark adapted and submitted to saturation pulse. A photo of the PSII efficiency (Fv/Fm) and of the maximal fluorescence Fm were captured every test week. The false colour code ranges from black (0.000) to magenta (1.000).

During the experiment, the measurements were performed on the central part of the slabs. The latter were pre conditioned in the dark. The initial fluorescence (F0) was obtained after 30 minutes of dark adaptation. Maximal fluorescence $(\mathrm{Fm})$ was obtained with a saturating flash $\left(1 \mathrm{~s}, 1000 \mu \mathrm{mol} . \mathrm{m}^{-2} . \mathrm{s}^{-1}\right)$. The ratio of variable to maximal 
fluorescence $(\mathrm{Fv} / \mathrm{Fm})$ was calculated. The protocol for fluorescence measurement was similar to the one described by Genty [31], but the measurements were performed on attached leaves. The relative quantum yield of PSII (ФPSII) at steady state is defined as (Fm'-Fs)/Fm', where Fs and $\mathrm{Fm}^{\prime}$ are, steady state fluorescence and maximum fluorescence in the light $\left(\mathrm{PAR}=120 \mu \mathrm{mol}\right.$ photon. $\left.\mathrm{m}^{-2} \cdot \mathrm{s}^{-1}\right)$, respectively. .PSII represents the number of electrons transported by a PSII reaction centre per mole of quanta absorbed by PSII. Both photochemical (qP) and non photochemical quenching (qN) were calculated according to [32].

Data calculated for each parameter was the mean value from the three replicates. Fv/Fm, Fm and every treatment from the first to the fourth weeks of incubation were shown by fluorescence images of the control (Fig. 2).

ФPSII, qN and qP showed percentages calculated from the mean values. The control value was represented as being $100 \%$ and treated stone results were expressed relative to the control (Fig. 3).

\subsubsection{Statistical Analysis}

Triplicates for the stone slabs per treatment and per control were carried out. Data in Fig. (3) are presented with non parametric descriptors, and the variations of fluorescence parameters between the treated and the control slabs were statistically tested by applying the non parametric Mann and Whitney U test at the 0.05 probability level.

\section{RESULTS}

\subsection{Color Variations on Surface Stones}

Before the inoculation of treated stones, the influence of treatments on the natural stone color was assessed. No color change should be visible after a stone treatment [33], which corresponds to a global color variation $\Delta \mathrm{E}^{*} \mathrm{ab} \leq 3$ [34]. For the four treatments used in the present study, the observed color variation were between 1.1 and 1.9 (detailed data not shown) and revealed no significant change of color on the stone surface.

After four weeks of accelerated biofouling test, $\Delta \mathrm{a}^{*}$ was reported as shown in Fig. (1). The first week of measurements showed negative values for control and every treated stone except for P1. Control, P3 and P4 already had significant color variation, whereas $\mathrm{P} 1$ and P2 slabs had very weak $\Delta \mathrm{a}^{*}(0.23$ and -0.16$)$ that revealed no real color change at this stage. $\Delta \mathrm{a}^{*}$ for P3 treated stones was -6.3 , whereas the control values were -4.1 with algae colonization appearing more quickly than on control stones.

$\Delta \mathrm{a}^{*}$ values for the control became more negative for the rest of the test and reached a minimum at the third week . P1 results were negative from the second week onwards and decreased progressively until -8 . P2 values had low $\Delta \mathrm{a}^{*}$ throughout the testing time and thus this parameter remained unchanged. $\Delta \mathrm{a}^{*}$ for P3 decreased until the second week $(-10.2)$ and then stayed close to this value in the third and the fourth weeks (-9 and -10.5$)$. P4 results reached a minimum in the second week with -4.6 followed by color variations being less negative with -1.4 until the test ended.

\subsection{Detection of Algal Photosynthetic Activity}

Five fluorescence parameters were used in this study. The maximum quantum yield of Photosystem II Fv/Fm ratio and the maximum fluorescence Fm were shown in the imaging of algae development (Fig. 2). The effective quantum yield $\phi P S I I$, the non photo chemical quenching $\mathrm{qN}$ and the photo chemical quenching qP are given in (Fig. 3).

Every value from each treatment was compared to the control in the Mann and Whitney U test. The *symbol in graphs indicates significant differences $($ at $p<0.05)$ between treatment and controls. Fv/Fm ratio of control had the highest values (0.64) from the very first week, which was shown by the dark blue color (Fig. 2). Then, it decreased slowly to the end of the test (0.50). Values for P1 treated stones were nil in the first week and Fv/Fm signal appeared only in the second week. Then values were observed to be similar in the control for the third week (0.50). P2 results were very different because of the absence of Fv/Fm signal throughout the experiment. On the contrary, results obtained for P3 treated slabs were as high as the control's in the first week, which then decreased progressively but stayed high. Fv/Fm of P4 slabs were as high as the control's in the first and the second week of the test, which then decreased rapidly in the last week.

Fm imaging (Fig. 2), recorded on the control stones, showed increased fluorescence on the entire area from the first to the last week. On P3 treated slabs, the pattern was similar to the control. Fluorescence started in the first week over the entire surface and increased through the test weeks. Measurements on P1 treated slabs showed a weak signal in the first week, then Fm increased quickly in the following weeks. Thus, Fm parameter detected the fluorescence of algae 
earlier than the Fv/Fm ratio. P4 results showed fluorescence from the first week, and then fluorescence became heterogeneous on the slab and disappeared from the sides and then towards the center.

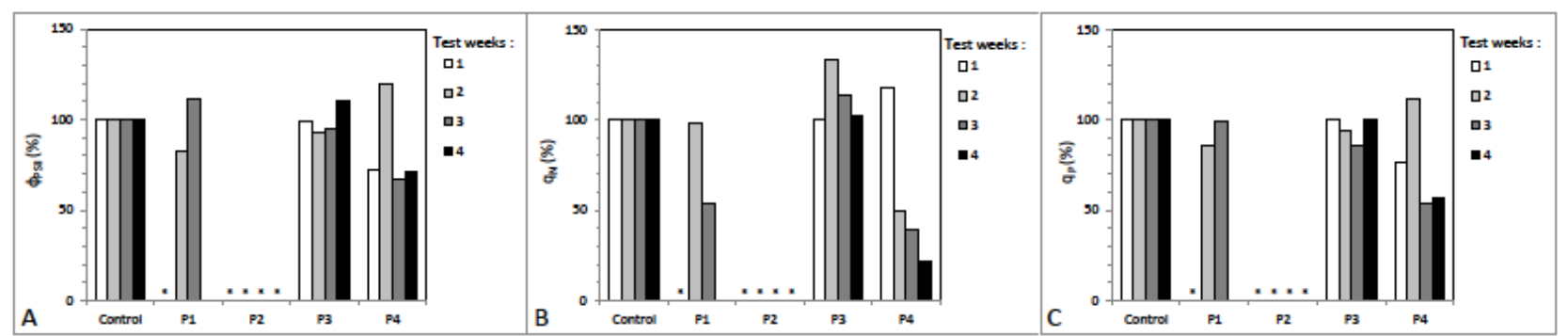

Fig. (3). ChlaF parameters of PSII in Chlorella vulgaris on control and on treated stones. The control value was chosen to represent $100 \%$ and the treated stones' values were expressed relative to control. * represent significant differences at $p<0.05$ compared to the control.

Fm decreased more slowly than Fv/Fm ratio. P2 results showed no maximum fluorescence from the starting to the end of the test.

The measured effective quantum yield QPSII showed that the fluorescence on P3 treated slabs was the same as that of the control's (Fig. 3A). On the contrary, P2 results displayed no detected signal throughout the experiment. On P1 treated slabs, no QPSII was measured in the first week so the QPSII was similar to the control in the second and the third week. P4 results showed weaker values than the control in the first week so the pPSII was similar to the control until the last week when the values decreased.

qN showed the same pattern as before Fig. (3B): P3 treated slabs had the same pattern as the control. P2 treated slabs had no qN, so the results were the opposite of the control. P1 treated slabs had no qN in the first week and then $\mathrm{qN}$ increased as much as the control but it decreased in the third week. qN measured in P4 treated slabs had the same values as the control for the first two weeks and then decreased until the end of the experiment.

qP measured on P3 treated slabs displayed similar results to the control (Fig. 3C). On P2 treated slabs, qP remained at zero as did the other parameters. P1 results showed nil values in the first week and similar values as the control in the other test weeks. qP measured on P4 treated slabs had lower values than the control in the first week and then increased the second week only to decrease again until the end of the test.

\section{DISCUSSION AND CONCLUSION}

The progressive decrease of $\Delta \mathrm{a}^{*}$ on the control throughout the test time frame reflected the algae growth over the entire stone surface. In regards to the treated stones, $\Delta \mathrm{a}^{*}$ displayed different patterns as compared to the control's. P3 treated stones revealed considerable algae development, close to that of the controls. Thus, P3 does not limit algae growth on the stone. On the contrary, P2 treated stones showed no greening and thereby no biocolonization. These results displayed the biocide effect of P2 treatment. $\Delta \mathrm{a}^{*}$ of P1 treated slabs showed progressive algae development which started only in the second week and was less intense than that of the controls. Thus, P1 treatment seemed to shift the spread of algae on the stone. On P4 treated stones, the growth of algae was different again: biocolonization started in the first week and increased until the second one. The last two weeks displayed a decrease in the extent of algae growth. Therefore, P4 treatment did not prevent algae colonization in the first two weeks but the biocide effect was effective in the last two weeks. Hence, the effectiveness of the P4 treatment was delayed. Consequently, $\Delta \mathrm{a}^{*}$ analysis allowed us to distinguish the various patterns of algae growth, according to the type of stone product.

ChlaF measurements added to the color results by identifying the influence of the biocidal effect on the photosynthetic process. ChlaF values (Fv/Fm, Fm images in Fig. 2) from control slabs were first analyzed and revealed ongoing photosynthetic activity even after one week of incubation. Nonetheless, after the first week, Fv/Fm decreased which suggests a decrease of the PSII activity despite the spread of (shown by color analysis). This result could be explained by the renewal of algae after the death of the first growth and the delay in the development of the new algae.

In the literature, Chlorella vulgaris culture in freshwater flasks displayed Fv/Fm $>0.63$ [18] that was similar to our 
data for the first test week but it stayed constant throughout the time frame whereas it decreased in our case. This divergent result was probably due to test conditions more suitable to easier algal growth in freshwater.

Another study [35] cultivated Chlorella vulgaris on concrete slabs in test conditions closer but still different from the present study's. Nonetheless Fv/Fm reached higher value (0.6) during the third or fourth test week then decreased to 0.534 which is closer to our data (0.488). That difference likely results from the water runoff experimental setting which favored a regular algal seeding and growth, thus the photosynthetic activity.

The comparison of the ChlaF of the four treatments to the controls revealed four different patterns already observed in the color analysis. The results of the P3 treated slabs corresponded to the first pattern where every fluorescence parameter had a similar value as the control. Therefore, the photosynthetic activity of algae was not disturbed by $\mathrm{P} 3$ treatment. On the contrary, P2 treatment had the opposite effect because all fluorescence parameters were nil, thus proving the effectiveness of $\mathrm{P} 2$ which inhibited the entire photosystem II.

ChlaF results obtained with P1 treatment were less clear than the others. Every parameter was nil in the first week except for Fm, whose image showed merely a slight early photosynthetic activity. ChlaF signals started only during the second week and indicated a delay in the algae photosynthetic activity. Color measurements showed a progressive increase of greening over time whereas, ChlaF analysis displayed a quick activation of the photosystem II. Despite different $\Delta \mathrm{a}^{*}$ values of the control and P1, ChlaF data of control and P1 were close from the second week onwards and revealed the complementarity of both techniques.

During the first week, ChlaF on P4 treated stones showed a weaker photosynthetic activity than on the controls but during the second week, all parameters were similar to the controls. Then, the PSII activity decreased until the end of the test. P4 treatment inhibited the photosystem II at the third week of the experiment as observed in the color analysis. Nonetheless, color data decreased and were constant from the last two weeks which suggests a stagnation in algae development. However,all fluorescence results proved a progressive inhibition of the PSII activity as clearly shown by the Fm image (Fig. 2). Consequently, the effect of the biocide on the photosystem II was delayed.

Regarding the combination of each product, P4 was made of TEOS with silver nitrate. This last component has a well known biocide effect on algae species [36] such as Chlorella [37, 38]. Nevertheless, in our study, $\mathrm{AgNO}_{3}$ had a more moderate biocide impact because of the delay in the inhibition of the algae development. Consequently, the $\mathrm{AgNO}_{3}$ concentration must be increased to make the biocide more effective. The P3 product was made of TEOS with silver nitrate and chitosan. The antibacterial and fungicide activity of chitosan $[22,23]$ should have enhanced the biocide effect of $\mathrm{AgNO}_{3}$ which would have optimized $\mathrm{P} 3$ activity.

The results were surprising because of the biocidal ineffectiveness of P3 but the silver/chitosan nanocomposites showed good compatibility [39]. By adding hydrophobic silica to the other components, while keeping the same concentration as in the P2 product, the photosystem II was completely inhibited. Therefore, the combination of TEOS, silver nitrate, chitosan and hydrophobic silica had good biocidal efficacy. P1 product had the same components as P2 but $\mathrm{AgNO}_{3}$ and hydrophobic silica concentrations were increased. Good biocidal effect was expected but measurements that showed a delay of the biocolonization with good efficacy in the first test week and then a quick growth of algae with considerable photosynthetic activity. The increased doses of both $\mathrm{AgNO}_{3}$ and hydrophobic silica in $\mathrm{P} 1$ had an unexpected effect because of a lower biocidal efficacy than P2. Thus the increase of $\mathrm{AgNO}_{3}$ and hydrophobic silica' doses did not improve the efficacy of the P1.

In conclusion, ChlaF is a non destructive technique that supplements the surface of color measurement and gives qualitative information on the photosynthetic performance of algae. Differences in color with $\Delta \mathrm{a}^{*}$ analysis showed a progressive greening of the stone control through the four test weeks in spite of a high photosynthetic activity in the first week then a progressive decrease. That suggested a delay in the renewal of algae with the senescence of the first algae. Biocide treatments displayed four different patterns of efficacy. P2 treatment made of TEOS with AgNO chitosan and hydrophobic silica at a low concentration inhibited the photosynthetic activity of algae. It had the best biocide effect of the four treatments. P1 treatment was biocide only the first week thus in a too short time. The biocide effect was not improved despite higher $\mathrm{AgNO}_{3}$ and hydrophobic silica's concentrations. P3 treatment had no effect to limit the algal growth. Hydrophobic silica missing in the combination led to no performance. P4 treatment made of only TEOS and $\mathrm{AgNO}_{3}$ had a late biocide effect that occurred only from the third week. Therefore the $\mathrm{AgNO}_{3}$ 's concentration was too weak to be efficient alone without chitosan and hydrophobic silica. In consequence the key to maximum impact is the synergy between ingredients $\left(\mathrm{AgNO}_{3}\right.$, chitosan and hydrophobic silica) and doses. If one or two 
of the active components are missing or the concentration is too high, the effectiveness of the treatment is compromised.

\section{CONFLICT OF INTEREST}

The authors confirm that this article content has no conflict of interest.

\section{ACKNOWLEDGEMENTS}

This work is funded by Interreg IV European grant (HYBRIPROTECH project), co financed by FEDER, Région Champagne-Ardenne, Conseil Général des Ardennes, Conseil Général de la Marne and la Wallonie. Many thanks to Grace Stockton for her precious help.

\section{REFERENCES}

[1] Koestler, R.J.; Warscheid, T.; Nieto, F. Biodeterioration: Risk Factors and Their management. Saving our architectural heritage: the conservation of Historic Stone Structures. Wiley J. \& Sons Ltd: New York, 1996; pp. 25-36.

[2] Warscheid, T.; Oelting, M.; Krumbein, W.E. Physico-chemical aspects of biodeterioration processes on rocks with special regard to organic pollutants. Int. Biodeterior., 1991, 28(1-4), 37-48. [http://dx.doi.org/10.1016/0265-3036(91)90032-M]

[3] Young, M.E.; Alakomi, H.L.; Fortune, I. Development of a biocidal treatment regime to inhibit biological growths on cultural heritage. Biodam. Environ. Geol., 2008, 56, 631-641.

[http://dx.doi.org/10.1007/s00254-008-1455-1]

[4] Urzi, C.; Krumbein, W.E. Microbiological Impacts on the Cultural Heritage. Durability and Change: The Science, Responsibility, and Cost of Sustaining Cultural Heritage. Wiley J \& Sons Ltd: New York, 1994; pp. 113-135.

[5] McNamara, C.J.; Mitchell, R. Microbial deterioration of historic stone. The Ecological society of America. Front. Ecol. Environ, 2005, 3(8), 445-451.

[http://dx.doi.org/10.1890/1540-9295(2005)003[0445:MDOHS]2.0.CO;2]

[6] Guillitte, O. Bioreceptivity: A new concept for building ecology studies. Sci. Total Environ., 1995, 167, $215-220$.

[http://dx.doi.org/10.1016/0048-9697(95)04582-L]

[7] Miller, A.Z.; Sanmartín, P.; Pereira-Pardo, L.; Dionísio, A.; Saiz-Jimenez, C.; Macedo, M.F.; Prieto, B. Bioreceptivity of building stones: a review. Sci. Total Environ., 2012, 426, 1-12.

[http://dx.doi.org/10.1016/j.scitotenv.2012.03.026] [PMID: 22534363]

[8] Guillitte, O.; Dreesen, R. Laboratory chamber studies and petrographical analysis as bioreceptivity assessment tools of building materials. Sci. Total Environ., 1995, 167(1-3), 365-374. [http://dx.doi.org/10.1016/0048-9697(95)04596-S]

[9] Fronteau, G.; Barbin, V.; Pascal, A. Impact of sedimentary diagenetic facies on weathering of carbonate building stone. CR Acad. Sci. Paris, 1999, 328, 671-677.

[10] Warscheid, Th.; Braams, J. Biodeterioration of stone: a review. Int. Biodeterior. Biodegradation, 2000, 46(4), $343-368$. [http://dx.doi.org/10.1016/S0964-8305(00)00109-8]

[11] Nugari, M.P.; Salvadori, O. Biocides and Treatment of Stone: Limitations and Future Propects. Proceedings of Art, Biology and Conservation: Biodeterioration of Works of Art. New-York, USA, 2003; pp. 519-535.

[12] Prieto, B.; Silva, B.; Lantes, O. Biofilm quantification on stone surfaces: comparison of various methods. Sci. Total Environ., 2004, 333(1-3), $1-7$. [http://dx.doi.org/10.1016/j.scitotenv.2004.05.003] [PMID: 15364515]

[13] Moreau, C.; Vergès-Belmin, V.; Leroux, L. Water repellent and biocide treatments: Assessment of the potential combinations. J. Cult. Herit., 2008, $9(4), 394-400$.

[http://dx.doi.org/10.1016/j.culher.2008.02.002]

[14] Tretiach, M.; Bertuzzi, S.; Salvadori, O. Chlorophyll a fluorescence as a practical tool for checking the effects of biocide treatments on endolithic lichens. Int. Biodeterior. Biodegradation, 2010, 64(6), 452-460. [http://dx.doi.org/10.1016/j.ibiod.2010.05.004]

[15] Borderie, F.; Tête, N.; Cailhol, D.; Alaoui-Sehmer, L.; Bousta, F.; Rieffel, D.; Aleya, L.; Alaoui-Sossé, B. Factors driving epilithic algal colonization in show caves and new insights into combating biofilm development with UV-C treatments. Sci. Total Environ., 2014, 484(1), 43-52.

[http://dx.doi.org/10.1016/j.scitotenv.2014.03.043] [PMID: 24686144]

[16] Eyssautier-Chuine, S.; Gommeaux, M.; Moreau, C. Assessment of new protective treatments for porous limestone combining waterrepellency and anti-colonization properties. Q. J. Eng. Geol. Hydrogeol., 2014, 47, 177-187. [http://dx.doi.org/10.1144/qjegh2013-026] 
[17] Cutler, N.A.; Viles, H.A.; Ahmad, S.; McCabe, S.; Smith, B.J. Algal 'greening' and the conservation of stone heritage structures. Sci. Total Environ., 2013, 442, 152-164. [http://dx.doi.org/10.1016/j.scitotenv.2012.10.050] [PMID: 23178775]

[18] Eggert, A.; Häubner, N.; Klausch, S.; Karsten, U.; Schumann, R. Quantification of algal biofilms colonising building materials: chlorophyll a measured by PAM-fluorometry as a biomass parameter. Biofouling, 2006, 22(1-2), 79-90. [http://dx.doi.org/10.1080/08927010600579090] [PMID: 16581672]

[19] Schreiber, U.; Bilger, W.; Neubauer, C. Chlorophyll fluorescence as a nonintrusive indicator for rapid assessment of in vivo Photosynthesis. In: Ecophysiology of Photosynthesis, Ecological Studies; Schulze, E.D.; Caldwell, M.M., Eds.; Springer-Verlag: Berlin, Heidelberg, 1994; Vol. 100, pp. 49-70.

[20] Ratte, H.T. Bioaccumulation and toxicity of silver compounds: a review. Environ. Toxicol. Chem., 1999, 18(1), 89-108. [http://dx.doi.org/10.1002/etc.5620180112]

[21] Runarsson, O.V.; Holappa, J.; Nevalainen, T. Antibacterial activity of methylated chitosan and chitooligomer derivatives: synthesis and structure activity relationships. Eur. Polym. J., 2007, 43, 2660-2671. [http://dx.doi.org/10.1016/j.eurpolymj.2007.03.046]

[22] Raafat, D.; Sahl, H.G. Chitosan and its antimicrobial potential-a critical literature survey. Microb. Biotechnol., 2009, 2(2), 186-201. [http://dx.doi.org/10.1111/j.1751-7915.2008.00080.x] [PMID: 21261913]

[23] Wang, D.; Li, H.; Wang, L.; Zhang, L.; Xu, Y. Effects of chitosan-RE ${ }^{3+}$-bentonite on growth of Chlorella vulgaris. J. Rare Earths, 2010, 28, 149-153. [http://dx.doi.org/10.1016/S1002-0721(10)60303-1]

[24] Wang, C.; Wu, A.H.; Lamb, R.N. Superhydrophobicity and optical transparency in thin films: Criteria for coexistence. J. Phys. Chem., 2014, $118(10), 5328-5335$.

[25] Fronteau, G. Comportements télogénétiques des principaux calcaires de Champagne-Ardenne, en relation avec leur faciès de dépôt et leur séquençage diagénétique; Ph.D Thesis, University of Reims Champagne-Ardenne: France, 2000.

[26] EN 1936. Natural Stone Test Methods - Determination of Real Density and Apparent Density, and of Total and Open Porosity; La Plaine Saint-Denis: France, 2007.

[27] European Committee for Standardization. EN 1925. Natural Stone Test Methods - Determination of Water Absorption Coefficient by Capillarity, AFNOR Edition; La Plaine Saint-Denis: France, 1999. AFNOR Edition

[28] European Committee for Standardization. EN 15803. Conservation of Cultural Property. Test methods. Determination of Water Vapour Permeability, AFNOR Edition; La Plaine Saint-Denis: France, 2010.

[29] Sajomsang, W.; Gonil, P.; Saesoo, S.; Ovatlarnporn, C. Antifungal property of quaternized chitosan and its derivatives. Int. J. Biol. Macromol., 2012, 50(1), 263-269.

[http://dx.doi.org/10.1016/j.ijbiomac.2011.11.004] [PMID: 22100980]

[30] European Committee for Standardization. EN ISO 11664-4. Colorimetry - Part 4: CIE 1976 L*a*b* Colour space, AFNOR Edition; La Plaine Saint-Denis: France, 2011.

[31] Genty, B.; Briantais, J.M.; Baker, N.R. The relationships between the quantum yield of photosynthetic electron transport and quenching of chlorophyll fluorescence. Biochim. Biophys. Acta, 1989, 990, 87-92. [http://dx.doi.org/10.1016/S0304-4165(89)80016-9]

[32] van Kooten, O.; Snel, J.F. The use of chlorophyll fluorescence nomenclature in plant stress physiology. Photosynth. Res., 1990, 25(3), 147-150. [http://dx.doi.org/10.1007/BF00033156] [PMID: 24420345]

[33] Sasse, H.R.; Snethlage, R. Methods for Evaluation of Stone Conservation Treatments; Wiley J \& Sons Ltd., 1996, pp. $223-43$.

[34] Moreau, C. Vieillissement naturel en milieu urbain de pierres calcaires hydrofuges: évaluation de la durabilité des traitements et de leur impact sur le nettoyage; Ph.D Thesis, University of Rheims Champagne-Ardenne: France, 2008.

[35] Manso, S.; De Muynck, W.; Segura, I.; Aguado, A.; Steppe, K.; Boon, N.; De Belie, N. Bioreceptivity evaluation of cementitious materials designed to stimulate biological growth. Sci. Total Environ., 2014, 481, 232-241.

[http://dx.doi.org/10.1016/j.scitotenv.2014.02.059] [PMID: 24602907]

[36] Loseva, NL The effect of $\mathrm{AgNO}_{3}$ on the bioenergetic processes and the ultrastructure of Chlorella and Dunaliella cells exposed to different saline conditions. Thermochim. Acta, 2007, 458(1-2), 71-76. [http://dx.doi.org/10.1016/j.tca.2007.02.015]

[37] Oukarroum, A.; Bras, S.; Perreault, F.; Popovic, R. Inhibitory effects of silver nanoparticles in two green algae, Chlorella vulgaris and Dunaliella tertiolecta. Ecotoxicol. Environ. Saf., 2012, 78, 80-85. [http://dx.doi.org/10.1016/j.ecoenv.2011.11.012] [PMID: 22138148]

[38] MacMullen, J.; Zhang, Z.; Dhakal, H.N. Silver nanoparticulate enhanced aqueous silane/siloxane exterior facade emulsions and their efficacy against algae and cyanobacteria biofouling. Int. Biodeterior. Biodegradation, 2014, 93, 54-62. [http://dx.doi.org/10.1016/j.ibiod.2014.05.009] 
[39] Cao, X.L.; Cheng, C.; Ma, Y.L.; Zhao, C.S. Preparation of silver nanoparticles with antimicrobial activities and the researches of their biocompatibilities. J. Mater. Sci. Mater. Med., 2010, $21(10)$, 2861-2868. [http://dx.doi.org/10.1007/s10856-010-4133-2] [PMID: 20652373]

Received: January 15, 2015

Revised: May 25, 2015

Accepted: July 31, 2015

(C) Eyssautier-Chuine et al.; Licensee Bentham Open.

This is an open access article licensed under the terms of the Creative Commons Attribution-Non-Commercial 4.0 International Public License (CC BY-NC 4.0) (https://creativecommons.org/licenses/by-nc/4.0/legalcode), which permits unrestricted, non-commercial use, distribution and reproduction in any medium, provided the work is properly cited. 